\title{
Symptomatology and Disease Intensity of Various Pyricularia grisea Isolates in Different Hosts
}

\author{
Tensirani Pradhan*, M. K. Mishra, Sandhyarani Nanda, \\ Biswajit Jena and Lipilipsa Priyadarshinee
}

\author{
Department of Plant Pathology, Odisha University of Agriculture and Technology, \\ Bhubaneswar, India \\ *Corresponding author
}

\section{Keywords \\ Symptomatology, Disease intensity, Host diversity, Pyricularia grisea}

\section{Article Info}

Accepted:

12 March 2020

Available Online:

10 April 2020

\section{A B S T R A C T}

Rice (Oryza sativa L.) is an important cereal crop and prone to many diseases out ofwhich, rice blast caused by Pyricularia grisea is of significant economic importance due to its destructive nature leading to serious yield loss. Blast infected leaves of rice, Panicum grass and finger millet were collected from different fields of OUAT farm, Bhubaneswar. Typical eye shaped or diamond shaped spots with pointed ends and ashy white center with reddish brown margin appeared on the leaves of rice, Panicum repens and finger millet. Different isolates of Pyricularia grisea from rice, Panicum and finger millet were isolated on oat meal agar and their cultural characteristics were studied. Pin prick method was followed to prove pathogenicity test and cross inoculation test produced typical symptoms at 15 days after inoculation. $P$. grisea isolates from rice, finger millet and Panicum repens produced maximum disease intensity $(78.52,85.18,81.48 \mathrm{PDI})$ in their respective hosts respectively. $P$. grisea isolates from rice and finger millet could not cause significant damage when inoculated in finger millet and rice plant respectively. $P$. grisea isolates from Panicum caused higher disease score of 4.07 (PDI 45.18) in rice than rice blast isolate in Panicum grass (score 2.67, PDI 29.62).

\section{Introduction}

Rice (Oryza sativa L.) is a self-pollinated cereal crop under family Poaceae. Rice is a staple food and mainstay for the human beings and their food security. It is widely cultivated in India, China, Indonesia, Bangladesh, Vietnam, Thailand, Myanmar,
Japan, Philippines and Brazil. In India it is cultivated in all the states mainly in kharif and rabi season.

Rice is prone to many pests and diseases which cause huge losses annually worldwide. Among all fungal diseases of rice, blast caused by Pyricularia grisea is of significant 
economic importance. Serious yield losses due to epiphytotic of blast disease have been recorded in different regions of India. In India first outbreak of blast was reported in 1918 in Tanjore district of Tamil Nadu and the estimated loss was 69\% (Thomas and Krishnaswamy, 1948). In 1952, rice crop was completely wiped out in Deras Farm of Odisha. The fungus Pyricularia grisea attacks at all stages of the crop and symptoms appear on leaf (leaf blast), collar region (collar blast), panicle neck node (neck rot) and panicle (panicle blast).

The symptoms are more severe in case of neck blast characterized by the infection at the panicle base followed by rotting. Leaf blast also is the most severe form of the disease causing yield loss. Rice is cultivated in all the three types of land i.e. upland, medium land and low land in both transplanted and broadcasting condition.

Rice based weeds i.e. Cyperus difformis, Cyperus iria, Cyperus rotundus, Digitaria setigera, Panicum repens and many others pose a great threat in terms of nutrient uptake and serving as collateral host of many fungal diseases of rice including blast. An experiment was conducted in the department of Plant Pathology, College of Agriculture, Bhubaneswar, Odisha with different Pyricularia grisea isolates collected from Panicum repens, rice and finger millet. Cross inoculations were made to see the intensity of blast disease in different hosts.

\section{Materials and Methods}

\section{Collection of disease samples and Isolation of pathogen}

Blast infected rice and Panicum grasses were collected from different fields of OUAT farm, Bhubaneswar during the month of October and November 2018. Blast infected finger millet leaves were collected from Centre for Pulses Research Station, Berhampur, OUAT. All the samples were collected carefully in polythene bags separately and brought to the laboratory for further study. The necrotic patches on the diseased leaves of rice, Panicum repens and finger millet were cut into small pieces having both healthy and diseased portion, surface sterilized by dipping in $0.1 \%$ mercuric chloride solution for 40 seconds and washed three times with sterilized water. The cut pieces were transferred to a sterilized petri dish containing oat meal agar medium aseptically and incubated at $27 \pm 1 \mathrm{C}$ for the development of fungal growth. Hyphal tip method was subsequently followed two to three times to get pure culture of the pathogen. Pure culture of the fungus was transferred to oat meal agar slants from the petriplate in aseptic condition. These slants were incubated at room temperature for the growth of the fungus and then stored in refrigerator for future study.

\section{Identification and maintenance of pure culture}

The fungus was identified according to available literature. Pure culture of the test fungus was sub-cultured on oat meal agar slants and incubated at $27 \pm 1^{0} \mathrm{C}$ for the growth of the fungus. These slants were preserved in refrigerator and sub-cultured every 30 days.

\section{Pathogenicity test}

Paddy and finger millet seeds were sown in earthen pots containing equal amount of sterilized soil and FYM (1:1). After emergence of the seedlings, artificial inoculation was done in growing seedlings. Seedling of Panicum grass were collected from the field and planted in pot and inoculated with respective Pyricularia grisea isolates. Pin prick method was followed for conducting pathogenicity test. In this method 
the leaves of test plants were cleaned with water and surface sterilized with $0.1 \%$ mercuric chloride solution with the help of cotton swab. These leaves were then subsequently washed with sterile water to remove the presence of excess mercuric chloride and allowed to dry. The upper as well as lower surface of the leaves was gently injured with the help of a sterilized needle. Spore suspension of ten days old culture of the test fungus was prepared and cotton swab was dipped in the spore suspension and spread on the upper and lower surfaces of the leaves.

The plants were tied with polythene cover and a cotton swab dipped in sterile water was placed inside it to provide humidity for development of disease symptoms. These plants were then labeled to distinguish them from control plants. The observations were recorded at 15 days after inoculation of the pathogen.

\section{Cross inoculation test in different hosts}

Seedlings of different hosts viz. rice, finger millet and Panicum repens were grown in nine pots (3 pots each) containing 5 plants/ pot. One month old seedlings were selected for artificial inoculation of respective isolates of Pyricularia grisea. Spore suspension of Pyricularia grisea from 10 days old culture was inoculated in the leaves of host plants by pin prick method. In rice plant, Pyricularia grisea isolate from Panicum grass (PPg) and Finger millet (FPg) were artificially inoculated by pin prick method. Similarly Finger millet plant was inoculated with Pyricularia grisea isolate from rice (RPg) and Panicum grass (PPg) and Panicumgrass was inoculated with Pyricularia grisea isolate from rice ( $\mathrm{RPg}$ ) and Finger millet (FPg) to conduct cross inoculation test. Observations were recorded after 15 days of inoculation using the following scales as per Directorate of Rice Research (DRR), Hyderabad (Table $1)$.

Table.1 SES Scale for leaf blast

\begin{tabular}{|c|c|}
\hline Score & Description \\
\hline $\mathbf{0}$ & No lesions \\
\hline 1 & Small brown specks of pinhead size without sporulating centre. \\
\hline 2 & $\begin{array}{c}\text { Small roundish to slightly elongated, necrotic grey spots, about } 1-2 \mathrm{~mm} \text { in } \\
\text { diameter with a distinct brown margin and lesions are mostly found on the lower } \\
\text { leaves. }\end{array}$ \\
\hline 3 & $\begin{array}{c}\text { Lesion type is the same as in scale } 2 \text {, but significant number of lesions are on the } \\
\text { upper leaves. }\end{array}$ \\
\hline 4 & $\begin{array}{c}\text { Typical sporulating blast lesions, } 3 \mathrm{~mm} \text { or longer, infecting less than } 2 \% \text { of the } \\
\text { area. }\end{array}$ \\
\hline 5 & Typical blast lesions infecting $2-10 \%$ of the leaf area. \\
\hline 6 & Blast lesions infecting $11-25 \%$ leaf area. \\
\hline 7 & Blast lesions infecting 26-50\% leaf area. \\
\hline 8 & Blast lesions infecting 51-75\% leaf area. \\
\hline 9 & More than $75 \%$ leaf area affected. \\
\hline
\end{tabular}


The percent disease index (PDI) was calculated by using following formula

$$
\mathrm{PDI}=\frac{\text { Sum of numerical rating }}{\begin{array}{c}
\text { Total numbers of plants observed } \\
\times \text { Maximum disease scale }
\end{array}} \times 100
$$

\section{Results and Discussion}

\section{Symptomatology}

The symptoms on rice leaves appeared as elliptical diamond shaped or eye shaped spots with pointed ends. The center of the spots was grey or whitish in colour with brown or reddish brown margin. Manibhushan Rao (1994); Casilla et al., (2009) and Padmanabhan (1974) reported similar symptoms in rice plant. Bonman et al., (1989) also reported the symptoms appeared on leaves, nodes, neck and panicles and symptoms were more severe in case of neck blast characterized by the infection at the panicle base followed by rotting. In the present investigation larger spindle shaped spots of 2-5mm length was found in Panicum leaves which were relatively larger than that of rice and finger millet. Finger millet blast symptoms were relatively wider than rice and Panicum repens.

\section{Pathogenicity test}

Rice and finger millet seeds were collected and grown in pots for about one month. Similarly small seedlings of Panicum repens were collected and raised in pots for conducting pathogenicity test. One month old seedlings of rice, finger millet and Panicum repens were inoculated with pure culture of Pyricularia grisea isolates from rice, finger millet and Panicum repens respectively by pin prick method and covered with polythene for the expression of the symptoms. Typical symptoms of water soaked, eye shaped spots with ashy center and dark brown margin were developed after 15 days of inoculation. More eye shaped symptoms were developed in the rice plant and coalesced to each other leaving large patches. Symptoms developed in Panicum repens were little rounded to oval and distributed more towards the middle with non-coalescing nature and larger than symptoms produced on rice and finger millet. Symptoms produced in finger millet were little different from those of rice and Panicum repens. Round to oval patches with dark brown margin and whitish black center were observed in leaf lamina 15 days after inoculation. The individual patches were much larger than that developed on rice and Panicum repens. Yoshida et al., (1992) also carried out punch method to the leaf blades of rice for production of symptoms. Workers like Kamalakannan et al., (2001) and Uddin et al., (2003) proved pathogenicity by spraying spore suspension with hand atomizer and sprayer respectively to get the symptoms.

\section{Host diversity study}

It was found that Pyricularia grisea isolates from rice, finger millet and Panicum repens produced maximum disease intensity in their respective hosts (Table 2). Maximum PDI of $78.52 \%$ was observed by Pyricularia grisea from rice in rice plants. Pyricularia grisea from Panicum repens and finger millet produced disease scores of 4.07(45.18 PDI) and 1.47(16.29 PDI) in rice host respectively suggesting little incompatibility of finger millet blast in rice. Pyricularia grisea from Panicum repens and finger millet also recorded highest PDI of $81.48 \%$ and $85.18 \%$ in their respective hosts. Pyricularia grisea from rice could produce least disease in finger millet with as low as 1.27 (14.07 PDI) disease score. It was found that Pyricularia grisea from rice and finger millet could not cause significant damage when inoculated in finger millet and rice respectively. 
Table.2 Disease reaction of different isolates of Pyricularia grisea against various hosts

\begin{tabular}{|l|c|c|c|c|c|c|}
\hline \multirow{2}{*}{\begin{tabular}{l}
\multirow{2}{*}{$\begin{array}{c}\text { Isolates of } \\
\text { Pyricularia grisea }\end{array}$} \\
\cline { 2 - 7 }
\end{tabular}} & \multicolumn{2}{|c|}{$\begin{array}{c}\text { Hosts } \\
\text { Rice }\end{array}$} & \multicolumn{2}{c|}{$\begin{array}{c}\text { Panicum grass } \\
\text { (Panicum repens })\end{array}$} & \multicolumn{2}{c|}{$\begin{array}{c}\text { Finger millet } \\
\text { (Eleusinecoracana) }\end{array}$} \\
\cline { 2 - 7 } & Score & PDI** & Score & PDI & Score & PDI \\
\hline RPg* & 7.07 & 78.52 & 2.67 & 29.62 & 1.27 & 14.07 \\
\hline PPg & 4.07 & 45.18 & 7.33 & 81.48 & 6.07 & 67.40 \\
\hline FPg & 1.47 & 16.29 & 5.87 & 65.18 & 7.67 & 85.18 \\
\hline
\end{tabular}

* RPg - Pyricularia griseafrom Rice, PPg - Pyricularia griseafrom Panicum repens, FPg -Pyricularia grisea from Finger millet ** PDI - Percent Disease Index

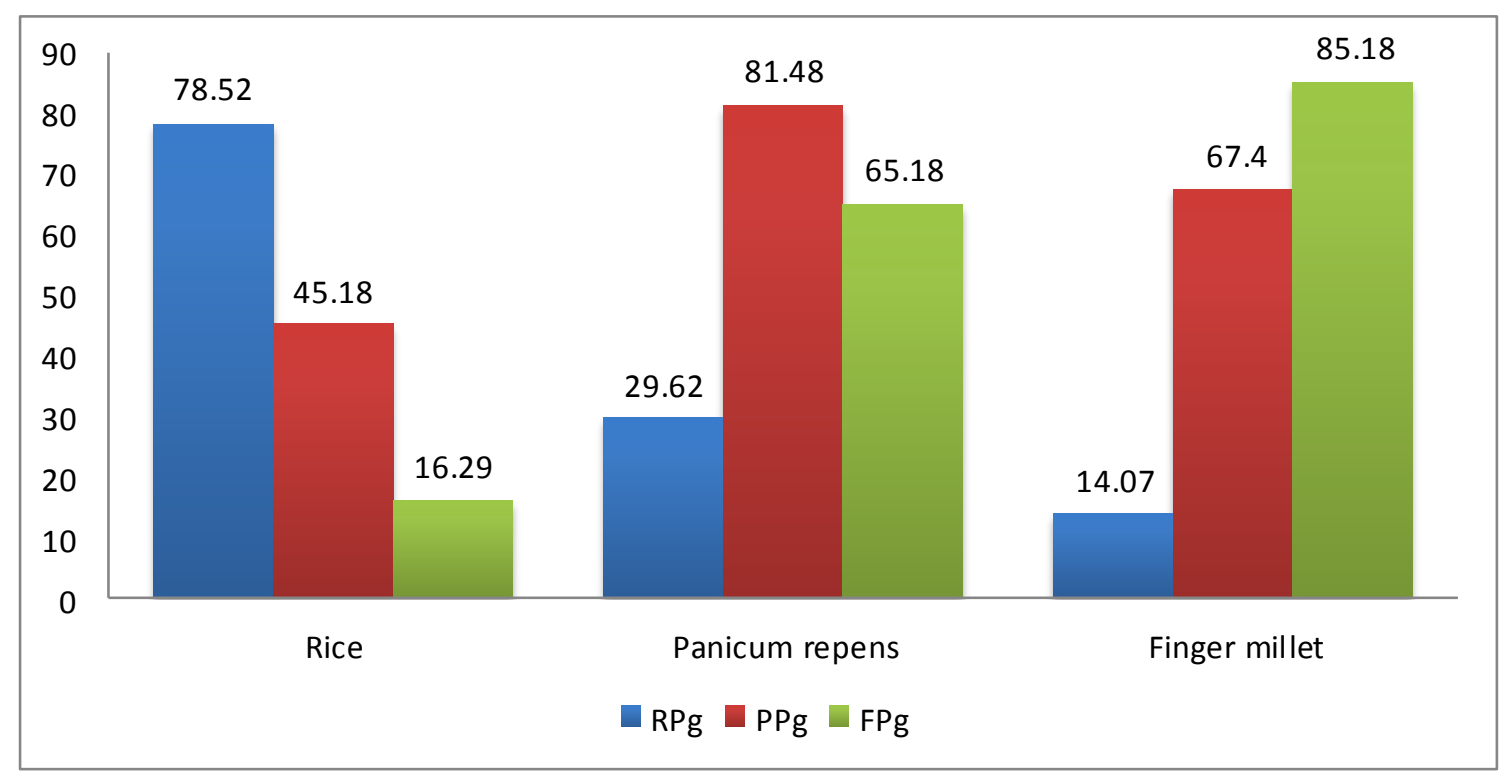

Figure.1 Percent Disease Index of Pyricularia grisea on different hosts

The finding was supported by Viji et al., (2000); Kato et al., (1977) and Todman et al., (1994). They reported that $P$. grisea from rice did not infect finger millet and vice versa. Pyricularia grisea from Panicum repens and rice when inoculated into each other's host produced moderate symptoms with PDI of $45.18 \%$ and $29.62 \%$ respectively.

Prabhu et al., (1992) reported $P$. grisea from weeds to be pathogenic to rice which confirmed the present investigation. Takan et al., (2004) reported $P$. grisea from weeds to be pathogenic to finger millet. In the present study Pyricularia grisea from finger millet and Panicum repens produced nearly similar disease score of 5.87 and 6.07 when inoculated in Panicum repens and finger millet respectively.

This suggested that $P$. grisea isolates from finger millet and Panicum grass can infect each other and would be regarded as source of blast pathogen in a particular area. In the current study it was also observed that Pyricularia griseafrom Panicum repens caused higher disease score (4.07) in rice than rice blast isolate in Panicum grass (2.67). It indicated Panicum blast to be highly virulent than rice blast (Table 1). 


\section{References}

Bonman JM, Estrada BA and Banding JM. 1989. Leaf and neck blast resistance in tropical lowland rice cultivars, Plant Disease, 73: 388-390.

Castilla N, Savary S, Veracruz CM and Leung H. 2009. Rice Blast: Rice Fact Sheets, International Rice Research Institute, pp. 1-3.

Kamalakannan A, Shanvnugam V and Surendran M. 2001. Effect of plant extracts on susceptibility of rice seedlings to blast disease and consequent biochemical changes in rice plant, Zeitschrift fur pflanzen krankheiten und pflanzenschutz,108 (5): 536-543.

Kato H, Yamaguchi T and Nishihara N. 1977. Seed transmission pathogenicity and control of ragi blast fungus and susceptibility of ragi to Pyricularia spp from grasses, cereals and mioga, Annals of the Phytopathological Society of Japan, 43: 392-401.

Manibhushan Rao K. 1994. Rice Blast Disease. 1st Ed., Daya Publishing House, Delhi.1.

Padmanabhan SY. 1974. Fungal Diseases of Rice in India. 1st Ed. Indian council of Agriculture Research, New Delhi. 15.

Prabhu AS, Fillipi MC and Castro N. 1992. Pathogenic variation among isolates of Pyricularia oryzae affecting rice, wheat, and grasses in Brazil. Tropical Pest
Management, 38: 367-371.

Takan JP, Akello B, Esele P, Manyasa EO, Obilana AB and Audi PO. 2004. Finger millet blast pathogen diversity and management in East Africa: A summary of project activities and outputs, International Sorghum and Millets Newsletter,45: 66-69.

Thomas KM and Krishnaswamy CS. 1948. The control of chief disease of rice as a means of increasing production, Madras Agriculture Journal, 34:1-8.

Todman AK, Pawar DR and Joshi MS. 1994. Host reactions to finger millet (Pyricularia grisea Sacc), Mysore Journal of Agricultural Sciences, 28: 45-46.

Uddin W, Viji G, Schumann GL and Boyd SH. 2003. Detection of Pyricularia grisea causing grey leaf spot of perennial ryegrass turf by a rapid immuno-recognition assay, Plant Disease, 87: 772-778.

Viji G, Gnanamanickam SS and Levy M. 2000. DNA polymorphisms of isolates of Magnaporthe grisea from India that are pathogenic to finger millet and rice, Mycological Research, 104(2): 161167.

Yoshida H, Reiichi $\mathrm{Y}$, Teruyoshi $\mathrm{H}$ and Yoshio E. 1992. Influence of Pyricularia oryzae on leaf growth in rice plant, Tohoku J. of Agriculture Research, 43(1-2): 1-8.

\section{How to cite this article:}

Tensirani Pradhan, M. K. Mishra, Sandhyarani Nanda, Biswajit Jena and Lipilipsa Priyadarshinee. 2020. Symptomatology and Disease Intensity of Various Pyricularia grisea Isolates in Different Hosts. Int.J.Curr.Microbiol.App.Sci. 9(04): 1624-1629.

doi: https://doi.org/10.20546/ijcmas.2020.904.190 